\title{
EXPANSIÓN Y DIVERSIFICACIÓN DE LA COMPAÑIIA GENERAL FABRIL FINANCIERA DURANTE LA INDUSTRIALIZACIÓN POR SUSTITUCIÓN DE IMPORTACIONES EN ARGENTINA, 1929-1958*
}

\section{EXPANSION AND DIVERSIFICATION OF THE GENERAL FABRIL FINANCIERA COMPANY DURING THE IMPORT SUBSTITUTION INDUSTRIALIZATION IN ARGENTINA, 1929-1958}

\author{
Silvia Badoza y Claudio Belini \\ Consejo Nacional de Investigaciones Científicas y Técnicas, Buenos Aires, Argentina \\ silviabadoza@gmail.com; claudiobelini@conicet.gov.ar
}

Resumen. Este artículo analiza la trayectoria del Grupo Fabril Financiera atendiendo a dos dimensiones centrales: el directorio como actor central, en tanto cabeza del grupo, en la definición de estrategias industriales y financieras, y en segundo lugar, las estrategias financieras seguidas por la empresa cabeza del grupo industrial, en especial el financiamiento del holding, a partir del archivo de la empresa entre la crisis de 1929 y el final de la etapa fácil de la industrialización por sustitución de importaciones (ISI). Estas dimensiones son abordadas desde una perspectiva de historia de empresas y sobre la base de archivo empresarial y otros repositorios. El estudio de este grupo industrial se propone contribuir con nueva evidencia empírica a la discusión más amplia sobre la participación de los grupos económicos y de las grandes empresas en el desarrollo económico de Argentina.

Palabras clave: historia de empresa; grupo industrial; Compañía General Fabril Financiera; siglo XX.

Abstract. The aim of this article is to analyze the trajectory of the Fabril Financiera Group focusing on two key aspects: first, the directory as the main agent and head of the group for the definition of industrial and financial strategies, and secondly, the financial strategies followed by the head company of the industrial group, especially in financial holdings, beginning with the company files between the crisis of 1929 and the final easy stage of the Import Substitution Industrialization (ISI). These dimensions are addressed from a historical perspective of the companies and are based on the company's files and other repositories. The objective of the study of this industrial

* Una versión previa de este trabajo fue presentada en las XXIV Jornadas de Historia Económica de la Asociación Argentina de Historia Económica, Rosario, octubre de 2014. Agradecemos los comentarios de Andrés Regalsky y de los evaluadores anónimos. Esta investigación contó con el apoyo financiero del Consejo Nacional de Investigaciones Científicas y Técnicas a través del subsidio para Proyectos de Investigación Plurianual núm. 377, 2011/2014.

Am. Lat. Hist. Econ., año 23, núm. 1, enero-abril, 2016, pp. 7-40 
group is to contribute new empirical evidence to the discussion about the participation of economical groups and large companies in the financial development of Argentina.

Key words: company history; industrial group; Fabril Financiera Company; xx century.

Fecha de recepción: 13 de noviembre de 2014. Fecha de aceptación: 28 de abril de 2015.

\section{INTRODUCCIÓN}

$\mathrm{E}$ n 1949, la Compañía General Fabril Financiera se presentó en un libro conmemorativo como "un grupo de empresas industriales en la Argentina" en la que "cada nueva actividad debía tener un vínculo industrial con la precedente" (CGFF, 1949, pp. 1-2). El Grupo Fabril, como se autodenominaba y era reconocido en el ámbito económico, se concentró tempranamente en el control de grandes empresas y una diversificación relacionada con sus actividades productivas en el complejo algodonero (desmotado e hilatura de algodón y fabricación de aceite) y en la industria gráfica. Desde su inicio, el Grupo Fabril emprendió la expansión hacia otras ramas a través de la inversión en valores y acciones de firmas que durante las siguientes décadas alcanzarían el liderazgo en sus respectivos sectores como La Papelera Argentina, Celulosa Argentina, Papelera del Norte y Papelera del Plata; las químicas Electroclor y Compañía Inquimar; la metalúrgica Talleres Coghlan, y las textiles Peinaduría e Hilandería de Lana, S. A. (en adelante PHILA) y Manufactura Algodonera Argentina, entre otras. En el caso de la producción de papel y celulosa impulsó una fuerte integración vertical y horizontal.

Continuando con la investigación realizada sobre la Compañía General de Fósforos (Badoza, 2008; Badoza y Belini, 2009; Belini, 2010), en este trabajo nos proponemos analizar, desde una perspectiva histórica y con un enfoque empírico, la trayectoria de la Compañía General Fabril Financiera. Esta firma encabezó uno de los grupos más importantes de Argentina durante la industrialización por sustitución de importaciones (en adelante ISI), entre 1930 y 1960. Desde el enfoque de la historia industrial, estas décadas están marcadas por la "etapa fácil" de la ISI. Desde la perspectiva de la empresa, este periodo coincide con el desarrollo del grupo industrial y con la prolongada presencia de un directorio que ejerció estos cargos hasta comienzos de la década de 1960, cuando finalmente se produjo el retiro de gran parte de esa "vieja guardia" directiva. Si bien en este artículo nos concentramos en el análisis de la cabeza del grupo, adelantamos algunos temas que hacen al conjunto de su estructura. 
Este artículo sostiene, contrariamente a lo afirmado por la historiografía, que Fabril Financiera se convirtió, desde finales de la década de 1930, en la cabeza de un grupo industrial conformado por empresas legalmente independientes cuyas actividades estaban relacionadas con los sectores industriales que constituyeron el núcleo productivo de la sociedad anónima. Para ello analizamos dos dimensiones: el directorio como actor central, en tanto cabeza de un grupo que domina la empresa madre y las firmas controladas por ella que impone las estrategias económicas y financieras $\mathrm{y}$, en segundo lugar, las políticas utilizadas para financiar la inversión en la producción directa y firmas asociadas.

La dirección de la empresa madre estuvo controlada durante 30 años por representantes de las familias fundadoras, tenedores mayoritarios y un grupo reducido de managers. Por cierto, todos ellos habían controlado la empresa predecesora, la Compañía General de Fósforos, y continuaron presentes en la etapa abierta en 1929. Esta dirección asumió la gestión de los negocios de Fabril, su transformación en la cabeza de un holding y la administración de las empresas controladas.

El directorio impuso una estrategia financiera que, tomando en cuenta el escaso desarrollo del mercado de capital local para las inversiones industriales, privilegió fundamentalmente el empleo de recursos internos a través de una intensa política de amortizaciones y la formación de nuevas reservas. En el marco de las décadas iniciales de la ISI, y especialmente en la segunda posguerra cuando la disponibilidad de crédito oficial se amplió, las estrategias de financiamiento de Fabril Financiera continuaron centrándose en el autofinanciamiento. Sostenemos que la composición y estabilidad del directorio permitió a la firma diseñar políticas financieras y productivas que reproducían la experiencia previa de la Compañía General de Fósforos durante el periodo agroexportador.

Desde el trabajo pionero de Leff (1978), los grupos económicos han concitado el interés de diversas disciplinas. Definidos como un conjunto de empresas autónomas que operan en diversos mercados y bajo un control financiero y empresarial común, los grupos económicos han asumido diversas formas en relación con su estructura, propiedad y gobierno corporativo. También se analizaron sus estrategias y su impacto en el desarrollo económico en los países de industrialización tardía en Asia y América Latina (Hikino y Amsden, 1995; Khanna y Yafhe, 2007). De manera reciente, los estudiosos han sostenido que los grupos constituyen una institución económica específica y que su presencia no es exclusiva de las "economías emergentes". Desde esta perspectiva, los grupos empresarios no evolucionarían linealmente hacia la empresa multidivisional, ni su presencia disminuiría a medida que las economías se desarrollan (Colpan, Hikino y Lincoln, 2010, pp. 6-8). 
En las últimas décadas se ha avanzado en el conocimiento sobre los grupos económicos del sureste asiático y, en menor medida, de América Latina. En este último caso, el interés se ha concentrado en el papel de los grupos en distintas experiencias nacionales desde finales del siglo XX (Aldrighi y Postali, 2010; Barbero y Jacob, 2008; Fracchia, Mesquita y Quiroga, 2010; Hoshino, 2010; Gaggero, 2012; Lefort, 2010). En contraste, son aún escasas las investigaciones de largo plazo en perspectiva histórica.

En América Latina, la presencia de grupos diversificados en el comercio, el agro, las finanzas y la industria han sido vistos como actores clave a la hora de explicar las divergentes trayectorias económicas (Dávila, 1996; Peres, 1998; Dávila, Vilora y Elías-Caro, 2013; Monsalve, 2014). Si bien los estudios se han concentrado en las trayectorias de los grupos diversificados no relacionados, en fechas recientes se ha comenzado a explorar otras experiencias. Mario Cerutti (2011) introdujo una distinción entre grupo económico y grupo industrial. Para este autor, un grupo industrial estaría conformado por "un conjunto de empresas autónomas pero fundamentalmente relacionadas: es decir, con actividades productivas, de distribución y de servicios muy vinculadas a su sector-eje" (p. 3). Esta conceptualización resulta valiosa a la hora de comprender las estrategias específicas de desarrollo de determinados grupos empresariales que sólo se diversificaron en actividades relacionadas.

En el caso de Argentina, la historia de empresas ha presentado dos visiones algo contrapuestas sobre las grandes firmas y el desarrollo industrial. Una, más crítica, ha resaltado que el control monopólico de los mercados y la capacidad de presión que ejercían sobre el Estado desalentaron los comportamientos innovadores por parte de las grandes empresas. Desde otra perspectiva, se enfatizó su dinamismo económico y se explicó su existencia, como en otros países latinoamericanos, por mercados de factores imperfectos (capital, recursos humanos, insumos) y la inestabilidad del entorno macroeconómico del país. En estas condiciones los grupos económicos alcanzaron economías de escala a pesar del límite impuesto por el tamaño del mercado interno (Barbero, 2000; Bisang 1996; Castro, 2008; Gilbert, 2003; Rougier, 2011; Schvarzer, 1989). En el caso de Fabril Financiera, Barbero (2000) ha resaltado los lazos étnicos italianos de la red empresarial y el estrecho vínculo financiero con el Banco de Italia y Río de la Plata. Más recientemente, esta idea fue reafirmada desde el análisis de las redes corporativas, confirmando que ese vínculo estaba basado en "una red de relaciones personales y en el entrecruzamiento de directorios" (Lluch y Salvaj, 2012, p. 143). Además, los trabajos no coinciden a la hora de definir quién era la cabeza del grupo. Algunos autores incluyeron a la Compañía General de Fósforos y Fabril Financiera en el denominado grupo italiano, liderado, según las diferentes interpretaciones, por Alfredo 
Demarchi (Schvarzer, 1996) o Antonio Devoto (Barbero 2000). Basándose en los archivos empresariales, Badoza (1997) lo ha caracterizado como grupo fabril. Finalmente, Aspiazu, Basualdo y Khavisse (1986) lo denominaron grupo celulosa, interpretando que la cabeza del grupo fue la empresa Celulosa Argentina, S. A. Esta discusión no constituye un tema menor a la hora de definir la empresa madre y la estructura del grupo.

El trabajo se apoya fundamentalmente en el archivo empresarial de la Compañía General de Fósforos y Fabril Financiera. El archivo empresarial (memorias y balances, libros de inventarios, libros de actas de directorio y de actas de asamblea general de accionistas) constituye un rico corpus documental que nos permite reconstruir la complejidad adquirida por Fabril Financiera en este periodo.

La primera parte del artículo relata los orígenes de Fabril Financiera y analiza brevemente las características de su desarrollo. En el segundo apartado estudiamos a los accionistas y la dirección de Fabril. El análisis de la dimensión financiera es el tema del tercer apartado, donde estimamos la rentabilidad industrial y analizamos el papel que desempeñaron los recursos internos y externos en el financiamiento de la expansión y constitución de Fabril Financiera como grupo empresario. Por último, presentamos algunas consideraciones finales sobre el tema.

\section{LA TRAYECTORIA DE FABRIL FINANCIERA}

Fabril Financiera se conformó en 1929 como un desprendimiento de la Compañía General de Fósforos, una de las primeras sociedades anónimas industriales del país dedicada a la elaboración de un producto de consumo masivo para el mercado interno y con una posición dominante en el mercado a lo largo de su existencia. Después de 40 años de trayectoria fabril, en septiembre de 1929, el poder ejecutivo aprobó los estatutos que permitieron la conformación de dos nuevas sociedades anónimas: Compañía General de Fósforos Sudamericana y Compañía General Fabril Financiera. Esta última se quedó con los establecimientos relacionados con la industria textil, algodón, aceite, artes gráficas y la empresa La Papelera Argentina, controlada desde 1926. En 1935, Fabril Financiera se desprendió definitivamente de la tenencia accionaria en la Sudamericana de Fósforos.

Los primeros 30 años de Fabril Financiera estuvieron marcados por la intensificación de la integración vertical y horizontal. La participación en distintas actividades productivas a través de la formación de sociedades jurídicamente independientes fue acompañada de eslabonamientos hacia atrás y adelante en las ramas papelera, química, gráfica y textil. A partir de mediados de la década de 1930, Fabril Financiera ingresó en Celulosa 
Argentina e incrementó su participación societaria en La Papelera Argentina. Ambas firmas, controladas por Fabril Financiera, produjeron pasta de celulosa a gran escala por primera vez en el país. Con Celulosa Argentina comenzó un marcado proceso de integración vertical de eslabonamientos productivos hacia atrás (Badoza y Belini, 2013). Mientras que en la rama del papel continuó la expansión horizontal, comenzada en la década de 1920 con La Papelera Argentina, mediante la adquisición de La Papelera del Plata (1940) y Papelera del Norte (1942).

Otros eslabonamientos hacia atrás se dieron a través de la creación de Electroclor, en 1938, y de Inquimar, tres años más tarde. La primera como productora de derivados químicos (soda cáustica, cloro y derivados) estaba ligada al proceso de elaboración de la celulosa. Por su parte, Inquimar estuvo vinculada a las artes gráficas, principal actividad industrial de la empresa madre, como productora de alcoholes, acetona y tintas.

En el contexto de la segunda guerra mundial, el grupo diversificó sus inversiones en el complejo textil con eslabonamientos hacia atrás por medio de la creación, en 1942, de Talleres Coghlan. Esta firma fue la primera y más importante fábrica del país hasta la década de 1960, especializada en la construcción de maquinaria textil y equipos para la industria papelera. La inversión en la industria textil, limitada hasta 1946 a la hilandería de algodón en Bernal, se amplió en ese año hacia la subrama lanera con la creación de PHILA. A comienzos de la década de 1950, Fabril Financiera comenzó la integración horizontal en la rama algodonera con la adquisición de la mayoría del paquete accionario de Manufactura Algodonera Argentina, S. A. (MAASA), la segunda tejeduría más importante del país. ${ }^{1}$

A estos emprendimientos industriales se agregó en 1940 la Compañía Inmobiliaria Victoria, S. A., la única sociedad no industrial del grupo, en la que participaban como accionistas Fabril Financiera, Celulosa Argentina, La Papelera Argentina y La Papelera del Plata. La Compañía Victoria atendía los negocios inmobiliarios del grupo.

Al finalizar la segunda guerra, Fabril concentró sus esfuerzos en un ambicioso plan de reequipamiento de maquinarias y construcciones en sus fábricas. A mediados de 1947 finalizaron los estudios de reformas y ensanches de todas las industrias que habían requerido el envío de técnicos al extranjero. El total de la inversión para las industrias propias oscilaba entre 25000000 y 30000000 de pesos corrientes, aunque fue postergado por diversas circunstancias hasta comienzos de la década de 1950.

${ }^{1}$ En octubre de 1950, diversas firmas del Grupo Fabril Financiera compraron 139546 acciones al Grupo Bemberg por un valor de 13546000 pesos corrientes. En 1952, Perón incluyó a Manufactura Algodonera Argentina, S. A., entre las firmas nacionalizadas del Grupo Bemberg, por considerar que la operación de transferencia al grupo Fabril encubría una maniobra tendente a ocultar las propiedades del primero. Fabril Financiera recuperó la empresa en 1958. 
En las empresas del holding, Fabril Financiera también alentó inversiones: "Las varias sociedades vinculadas a nuestra Compañía y fomentadas por nuestra iniciativa, como las de celulosa, papel, química y plantaciones, han estudiado y empezado a poner en práctica importantes y numerosos proyectos de ensanches y reformas en los cuales invertirán 90000000 de pesos moneda nacional." 2

En la década de 1950, la empresa debió enfrentar los contratiempos de los ciclos de marchas y contramarchas de la economía local. En este periodo, las memorias muestran una nueva y reiterada preocupación: la búsqueda de eficiencia y productividad a través de la racionalización y la "reorganización de relaciones industriales y humanas", primero en la textil de Bernal y posteriormente en sus propios talleres gráficos ubicados en el barrio de Barracas, al sur de la ciudad de Buenos Aires. Para entonces, era necesario reestructurar las plantas fabriles y reorientar los productos destinados al mercado. En alguna medida, las dificultades que atravesaban la industria textil y la gráfica explicaban la pérdida de importancia en los ingresos provenientes de sus fábricas. En esos años los beneficios de la producción fueron menores a los percibidos por la tenencia de acciones de las empresas controladas y ligadas a Fabril Financiera.

¿Cuáles eran las sociedades con fuerte participación del grupo Fabril como accionista? En 1948, la rama de celulosa y papel se ubicaba en el primer lugar con $61 \%$ del capital suscrito por Celulosa Argentina, 67\% de La Papelera del Plata, y 41\% de La Papelera Argentina. En segundo lugar, y muy por detrás del papel, se ubicaban empresas en diversos sectores como Talleres Coghlan, con 95\%. En tercer lugar se ubicaba la textil PHILA, con $60 \%$ del capital suscrito, y continuando luego las empresas químicas Inquimar, 76\%, y Electroclor, 2\%. La participación del grupo Fabril en el sector financiero estaba limitada al Banco de Italia y Río de la Plata, alcanzando $11 \%$ del capital suscrito por esa entidad bancaria. ${ }^{3}$

Al final del periodo en estudio, en 1957, la inversión de Fabril Financiera por sectores se distribuía del siguiente modo: $71 \%$ del valor de libro de las acciones correspondía a la rama de celulosa y papel (Celulosa Argentina, La Papelera Argentina y Papelera del Plata); 18\% a las industrias varias (Talleres Coghlan, Fieltros Industriales y Pirelli); 7\% a la rama textil (Manufactura Algodonera, PHILA y SNIAFA); 3\% a la rama química (Inquimar y Electroclor), y sólo $1 \%$ a inversiones no industriales, el Banco de Italia y Río de la Plata.

\footnotetext{
${ }^{2}$ Libro de Actas de Asamblea General de Accionistas, núm. 2, 58 Asamblea, 27 de junio de 1947, fol. 132. Archivo empresarial de la Compañía General de Fósforos y Fabril Financiera (en adelante CGFF).

${ }^{3}$ Libro de inventario, núm. 3, fols. 312-313, CGFF.
} 
¿Qué lugar ocupaba Fabril Financiera y las sociedades controladas por ella en el mercado argentino? En 1956, tres de las empresas del grupo estaban entre las 20 primeras empresas por mayores ventas: Celulosa Argentina se ubicaba en el sexto lugar, Fabril Financiera se encontraba en el puesto décimo tercero y La Papelera Argentina en el décimo quinto. Las ventas de Fabril Financiera alcanzaban la tercera parte de las firmas que encabezaban el ranking. Molinos Río de la Plata y la Sociedad Industrial de Amasadoras Mecánicas (SIAM) (Camoatí, enero, 1957, núms. 198-200, p. 3).

En el contexto de la ISI, Fabril Financiera constituyó una excepcionalidad tanto por su origen ligado a la firma industrial Compañía General de Fósforos, como por la concentración de sus inversiones en el sector manufacturero. La sociedad dominante del grupo tuvo un perfil eminentemente industrial. A través de estrategias de integración vertical y horizontal impulsó una diversificación en actividades industriales relacionadas con la producción de la empresa madre: la gráfica y la textil. Por su especialización manufacturera, Fabril Financiera puede ser pensada como un grupo industrial. Esto marcó una diferencia con otros grupos existentes durante el periodo estudiado, como Tornquist, Bemberg o Bunge y Born, que se expandieron hacia diversos sectores de la economía no relacionados a partir de un origen comercial y financiero. Estos casos conformaron grupos económicos que, como los definió Valdaviso (2002), estarían integrados "por un gran número de empresas, generalmente sociedades anónimas formalmente independientes unas de otras, que operan en sectores de actividad muy diversos, pero bajo el control empresarial y financiero de una empresa matriz, una sociedad holding, un banco o, simplemente, de una o varias familias directamente" (pp. 582-583).

\section{LOS ACCIONISTAS Y LA DIRECCIÓN DE FABRIL FinANCIERA}

La dirección y la estructura de propiedad son dos dimensiones clave para explicar la toma de decisiones y las estrategias de desarrollo de la firma. La empresa gerencial moderna con una separación entre propiedad y gestión (Chandler, 1987 y 1996) ha sido más una excepción, limitada a Estados Unidos, que un modelo difundido a escala mundial. El control de las familias sobre el gobierno corporativo ha sido más extenso de lo que se ha pensado en el pasado. La presencia de grupos económicos controlados por familias y con estructuras piramidales ha predominado en todo el mundo (La Porta, Lopez-de-Silanes y Shleifer, 1999; Morck, 2005). En Argentina, los estudios sobre los grupos económicos más antiguos (Bemberg, Bunge y Born y Tornquist) han destacado la continuidad de las familias en el control y gobierno corporativo. 
En el caso bajo estudio, las principales familias accionistas de la Compañía General de Fósforos continuaron detentando durante la década de 1930 una parte importante de las acciones de Fabril Financiera, aunque vieron disminuida su participación. En 1929, el grupo Dellachá era el principal accionista con 39019 acciones (19.5\% del total). Para 1936, permanecieron como los mayores tenedores de acciones, aunque su participación había declinado a 14.2\%. La familia Lavigne incrementó su participación, ascendiendo de $6.1 \%$ a $7.6 \%$ del capital total en estos años. Por el contrario, en el caso de los Devoto, las acciones repartidas entre los herederos de la sucesión de Antonio Devoto, que alcanzaban 21548 acciones (10.7\%), en apenas seis años disminuyeron a 2.3\%, mientras que la viuda de José Devoto conservó su participación en alrededor de 4.6\%. Los Profumo también retuvieron su modesta participación de $0.9 \%$. En conjunto, los accionistas originarios y sus herederos pasaron de controlar $42 \%$, en 1930 , a poseer 30\% en 1938 .

A diferencia de los otros grupos económicos, Fabril Financiera no tuvo un vínculo estrecho con entidades bancarias. Las instituciones financieras participantes como accionistas en la Compañía General de Fósforos en 1929 eran el Banco de Italia y Río de la Plata con 4654 acciones, el Anglo Sudamericano con 6655 y la Banca Svizzera Italiana, radicada en Lugano, con 3343 acciones. En los inicios de Fabril Financiera, el Banco de Italia y Río de la Plata conservó igual participación accionaria, lo que representaba sólo $2.3 \%$ del capital. Este dato refuerza nuestra hipótesis sobre la débil presencia del banco como uno de los accionistas principales y menos aún, como cabeza del grupo (Badoza y Belini, 2009). Los otros bancos no tuvieron una presencia estable ni fueron accionistas importantes. La Banca Svizzera Italiana no participó en Fabril Financiera; mientras que el Anglo Sudamericano incrementó su participación hasta alcanzar 7325 acciones en 1931 (3.6\% del capital integrado), desapareciendo como accionista en el marco de la crisis mundial. En síntesis, esto demuestra el escaso peso que tuvieron las entidades financieras en la cabeza del holding.

$\mathrm{El}$ archivo de la empresa sólo nos permite conocer quiénes fueron los principales accionistas hasta 1938, aunque a partir de la reconstrucción de las acciones depositadas en las asambleas tenemos información sobre el nivel de concentración de la tenencia de acciones. En 1930, de las 200000 acciones emitidas, 101 accionistas depositaron para la asamblea $72 \%$ del total; como se dijo más arriba, solamente cuatro familias accionistas detentaban $42 \%$. Once años más tarde, sólo 37 inversores depositaron $62 \%$ del total de acciones suscritas que ascendían a 240 000. En este caso, si bien la cantidad de depositantes se redujo a poco más de un tercio, el porcentaje de acciones presentadas disminuyó en apenas 10\%. Este último dato revela que en los inicios del grupo Fabril fue muy notable la concentración de 
acciones en pocas manos. ${ }^{4} \mathrm{La}$ falta de estudios para este periodo sobre la estructura de propiedad de otras empresas argentinas y las disparidades nacionales a la hora de definir los diferentes niveles de concentración de las acciones, impiden comparar este caso.

En la década siguiente, y a medida que se conformaba el grupo Fabril, se produjeron cambios en la estructura de propiedad de este al incorporarse por entrecruzamiento de acciones las empresas controladas o ligadas. En 1950, la participación de estas alcanzó casi 19\% del capital del holding. Esta participación estaba distribuida entre tres empresas: La Papelera Argentina, con 166798 acciones (9.8\%); La Papelera del Plata, con 84504 (5\%), y Celulosa Argentina, con 60871 acciones (3.6\%). En 1958, probablemente las familias fundadoras, los directivos y las empresas del holding formaban la parte principal de los 124 accionistas que depositaron 59\% de las 4405327 acciones suscritas.

$\mathrm{Al}$ control de la propiedad accionaria se sumó la presencia de las familias fundadoras en el Consejo de Administración que, junto con un conjunto de managers, llevaron adelante los negocios hasta comienzos de la década de 1960. A lo largo del periodo hubo cambios en el número de miembros del organismo de dirección, pero su composición no se modificó sustancialmente. El cuerpo directivo, elegido anualmente por la Asamblea General de Accionistas estuvo compuesto entre 1930 y 1938 por siete miembros. Además, los síndicos, nombrados por la misma mayoría que elegía al directorio, eran hombres de confianza y vinculados estrechamente al mismo. Esta situación disminuía la independencia del síndico respecto a la dirección y al grupo mayoritario de accionistas, debilitando su tarea fiscalizadora. ${ }^{5}$ Sucesivas reformas del estatuto de la firma elevaron el número de directores hasta nueve titulares en $1949 .{ }^{6}$

${ }^{4}$ En 1929, el estatuto de Fabril Financiera establecía un mínimo de 20 acciones para tener derecho a voto en las asambleas. A finales de la década, una reforma impuso algunas limitaciones a la concentración del poder en manos de los accionistas mayoritarios. El artículo 37 fijaba que una acción daba derecho a un voto y establecía que "ningún accionista, cualesquiera sea el número de acciones que posea o represente tendrá derecho a más del décimo de todos los votos de las acciones suscriptas y realizadas del capital realizado de la Compañía, ni a más de dos décimos de todos los votos conferidos a las acciones presentes o representadas en la asamblea" en CGFF (1938, p. 18).

${ }^{5}$ Juan Rivara ocupó el cargo de síndico suplente dejado por Balbi en la Compañía General de Fósforos. En 1920 fue elegido síndico titular, cargo que continuó ocupando luego de 1929 en la Compañía General Fabril Financiera hasta 1949. Desde 1950 hasta su fallecimiento en 1952 se desempeñó como director. Hugo Bagnardi fue síndico suplente de Fabril Financiera desde 1934 hasta 1949 y, en reemplazo de Rivara, fue síndico titular entre 1950 y 1957. Desde 1958 hasta 1960 fue director titular. Bagnardi era un reconocido agente de la bolsa; desde 1910 hasta 1945 presidió Bagnardi, S. A. Sociedad de Bolsa, al tiempo que dirigió junto a Balbi la sociedad anónima, financiera, industrial, ganadera y agrícola Balbi \& Bagnardi.

${ }^{6}$ Desde entonces desaparecieron los directores suplentes que reemplazaban en caso de ausencia a un miembro titular. Esta reforma desplazó a David Gómez Pombo, representante de los Devoto en el directorio entre 1928 y 1949. 
Quiénes podían ser electos como directores, cómo se elegían y cuántos eran, la duración de sus cargos, su retribución, las posibilidades de reelección, etc., debían ajustarse a lo establecido en el Código de Comercio Argentino. ${ }^{7}$ Este conjunto de normas y el dominio de los accionistas mayoritarios dieron lugar a la permanencia de un grupo estable en la dirección.

A esto se sumaba la obligatoriedad de depositar acciones para participar y ser elegido como director. ${ }^{8}$ Algunos detentaban un importante número de acciones y otros tenían cantidades modestas. Para 1938 el presidente del directorio Vittorio Valdani, el vicepresidente Juan Balbi, el tesorero Emilio Lavigne y dos de los directores vocales, Andrés Scotto y Francisco Prati, poseían en conjunto 7\% de las acciones suscritas. En este caso no se dio la separación entre propiedad y gestión de la empresa, dirigida por administradores sin participación en el capital y sin control por parte de los accionistas propietarios (Hilt, 2014; La Porta, Lopez-de-Silanes y Shleifer, 1999). En Fabril Financiera las familias con importante tenencia accionaria no tenían dificultades para controlar la gestión a través de su participación en la alta dirección. La mayoría de los directivos permanecieron durante todo el periodo examinado. Esta continuidad puede explicarse por la ausencia de una restricción legislativa en la reelección y por la política "endogámica" de escoger a los directores dentro del círculo de las familias accionistas, directivos de carrera de la propia empresa y, en menor medida, de las otras sociedades anónimas que conformaban el holding.

De los 21 miembros titulares, suplentes y síndicos que formaron el directorio en distintos momentos, la mitad provenían de la dirección de la Compañía General de Fósforos: Vittorio Valdani, Juan Balbi, Emilio Lavigne, Enrique Scotto, Francisco Prati, Manuel Montes de Oca, Antonio Alemanni, David Gómez Pombo, Ángel Ambrosetti y el síndico Juan Rivara. Todos ellos recorrieron distintas posiciones en la alta dirección de Fabril. Algunos fueron convocados por su formación y conocimientos industriales, financieros o jurídicos. Entre ellos se destacaron Valdani, Balbi y Prati, quienes detentaron los más altos cargos de la empresa. La carrera de Valdani, ingeniero industrial egresado del Politécnico de Milán en 1894, fue la más emblemática. Fue nombrado gerente general en 1908. Diez años más tarde ingresó al directorio como tesorero. Entre 1920 y

\footnotetext{
${ }^{7}$ Respecto a las retribuciones, Fabril Financiera continuó con la política de reparto de las utilidades asignadas al directorio. Del total de los beneficios realizados, separó 6\% para la retribución del órgano ejecutivo. El reparto se hacía en forma proporcional a la asistencia de cada uno de los directores a las reuniones. A ese honorario se agregaban los sueldos o remuneraciones adicionales por desempeño en comisiones técnicas, especiales o administrativas por hasta $25 \%$ de las utilidades.

${ }^{8}$ Hasta 1946 debían depositar 100 acciones que representaban 10000 pesos corrientes, y luego de la reforma de los estatutos de ese año, 500 acciones.
} 
1925 ocupó en tres oportunidades la vicepresidencia, y al año siguiente fue elegido presidente. Valdani fue el encargado de la negociación que condujo a la división de la Compañía General de Fósforos en 1929, hecho que implicó una delicada negociación, principalmente con la familia Dellachá, accionistas mayoritarios y residentes en Italia. Entre 1929 y 1961, Valdani presidió Fabril, salvo el interregno 1942-1947, en que debió alejarse de la presidencia por su conocida adhesión al fascismo y su inclusión en la lista elaborada por los aliados.

Juan Balbi, un hombre proveniente de la Bolsa de Comercio y con vínculos en el mundo financiero a través de la firma Balbi \& Bagnardi, ingresó en 1912 como síndico suplente. En 1918 fue elegido tesorero y nueve años más tarde accedió a la vicepresidencia y continuó en el mismo cargo hasta 1942. Desde ese último año reemplazó a Valdani en la presidencia hasta 1947, cuando falleció. Por su trayectoria en la Bolsa y en la Compañía General de Fósforos, Balbi logró vincularse al Banco de Italia y Río de la Plata en 1921, institución en la que fue elegido presidente en 1929.

El ingeniero industrial Francisco Prati, egresado del Politécnico de Turín en 1910, ingresó en 1919 en el departamento técnico de la Compañía General de Fósforos, ascendiendo en 1925 a subgerente. En Fabril Financiera continuó en el mismo cargo hasta 1932, en ese año fue nombrado director gerente. Paralelamente, entre 1933 y 1946 fue vocal del directorio. En la Asamblea de Accionistas de ese último año, y mientras Valdani continuaba ausente del consejo de administración, fue nombrado vicepresidente delegado, cargo que detentó hasta su renuncia en $1961 .{ }^{9}$

Un caso diferente de acceso al directorio fue el de los accionistas mayoritarios, como los Lavigne. La presencia del arquitecto Emilio Lavigne estuvo relacionada con la pertenencia a una de las familias fundadoras de la Compañía General de Fósforos. Ingresó en 1909 y fue elegido en distintos cargos, desde secretario a vicepresidente. En Fabril, fue tesorero hasta 1942. A partir de ese año y hasta 1945, como resultado de la renuncia de Valdani, ocupó la vicepresidencia en reemplazo de Balbi. Desde 1946 y hasta su fallecimiento en 1957, fue secretario. En total estuvo en el directorio de ambas sociedades anónimas por 48 años. A la muerte de

${ }^{9}$ Por cierto, el departamento técnico continuó proveyendo de directores a Fabril. Oscar Sassoli, nacido en Montevideo en 1907, se radicó en Argentina en 1919 y se graduó de ingeniero civil en la Universidad de Buenos Aires. En 1929 se incorporó a Fabril como ingeniero del departamento técnico y en 1943 fue designado subgerente. Tres años más tarde ocupó el cargo de gerente general dejado por Prati, que continuó desempeñando hasta el final del periodo estudiado. Desde septiembre de 1961 hasta abril de 1964 fue nombrado vicepresidente. Posteriormente fue elegido presidente entre mayo y octubre de 1964, renunciando al cargo por problemas de salud. Carpeta Oscar Sassoli, CGFF. En el caso de Sassoli, al igual que anteriormente Valdani y Prati, la alta capacidad gerencial para ocupar los máximos cargos del directorio estuvo marcada por los conocimientos técnicos y la experiencia obtenida en su extensa trayectoria en Fabril. 
Emilio Lavigne fue nombrado síndico suplente el ingeniero Juan Manuel Lavigne. Desde 1958 fue síndico titular y continuó en el cargo después de nuestro periodo de estudio. ${ }^{10}$

Sin embargo, no siempre las familias con mayor tenencia de acciones estuvieron representadas en el consejo de administración. Un ejemplo fue la familia Dellachá, sin cargo directivo entre 1904 y $1948 .{ }^{11}$ Recién este último año, Alberto Dellachá accedió a vocal titular, cargo en el permaneció hasta 1957. En ese año reemplazó a Emilio Lavigne como secretario del directorio.

La tercera vía de acceso fue el reclutamiento de managers entre las empresas que intercambiaban participaciones accionarias dentro del holding que encabezaba Fabril Financiera. La primera participación de este tipo fue la de Tomás de Estrada en la Compañía General de Fósforos. Su ingreso al directorio fue el resultado de la fusión de las empresas papeleras en la sociedad anónima La Papelera Argentina, ocupando la presidencia. Tomás de Estrada se incorporó a la compañía en 1926 como tesorero y continuó en ese cargo hasta 1928. En Fabril, fue elegido director titular hasta su fallecimiento ocurrido en 1936. El otro representante de La Papelera Argentina en el directorio de Fabril, entre 1932 y 1949, fue Francisco Giraldez, quien ingresó como vocal suplente y en 1941 fue elegido director titular, cargo que ocupó hasta su fallecimiento. El último en integrarse al directorio de Fabril fue Silvio Gagliardi, por Celulosa Argentina. Se desempeñó como director suplente entre 1941 y 1947. En 1948 ocupó un lugar como director titular. Desde 1949 a 1957 fue segundo vocal y desde entonces primer vocal del Consejo de Administración. La integración de estos tres empresarios demuestra que para Fabril el sector papelero constituyó el ámbito de las principales inversiones, y de hecho La Papelera Argentina y Celulosa Argentina se convirtieron por el entrecruzamiento de acciones en parte de la mayoría accionaria. Sólo de este sector y no de las inversiones en la industria algodonera, metalúrgica y química se incorporaron representantes en el directorio de la cabeza del holding.

En suma, en el directorio de Fabril Financiera se incorporaron pocos representantes de las empresas controladas. En contraste, la expansión y el control accionario por parte de Fabril Financiera de firmas líderes de la

${ }^{10}$ Un caso similar a los Lavigne fue el de los Scotto. Santiago Scotto ingresó en 1918 al directorio de la compañía. Dos años después, Enrique Scotto fue nombrado secretario en el mismo cuerpo directivo y continuó en Fabril Financiera hasta su fallecimiento en 1935. Andrés Scotto fue elegido vocal titular entre 1937 y 1942 y tesorero al año siguiente, continuando en la misma posición hasta el final del periodo bajo estudio. Mientras que Aldo Scotto ingresó como cuarto vocal titular en 1953 y en 1958 fue elegido director vocal primero.

${ }^{11}$ Alberto Dellachá rubricó las actas de asambleas de accionistas a partir de 1932, un año después de haber llegado a Argentina. 
época proporcionaron lugares destacados a sus directivos en las empresas que conforman el holding (véase cuadro 1). ${ }^{12}$

En este apartado hemos estudiado la tenencia de acciones y el control mayoritario por parte de un grupo de familias, algunos individuos y las empresas del grupo, y su relación con quienes asumen la dirección del holding y la gestión de los negocios de Fabril Financiera. Pudimos constatar que los tenedores mayoritarios impusieron a lo largo del periodo estudiado su representación en el directorio de la empresa madre. Dada la limitada información disponible para realizar un listado exhaustivo del conjunto de los accionistas, nos hemos valido para este estudio del análisis de los estatutos que reglamentan el gobierno corporativo y de las carreras de cada uno de los directivos que asumieron ese gobierno como vías complementarias para constatar el control ejercido por los accionistas mayoritarios. Por lo contrario, los accionistas minoritarios no obtuvieron representación en el gobierno y se limitaron a reclamar por el resguardo de sus intereses, entre ellos un mayor reparto de los dividendos en efectivo, aunque sin mucho éxito para imponerse. ${ }^{13}$

El control sobre la propiedad y la gestión por parte de ese conjunto de accionistas les permitió diseñar la política de diversificación relacionada e integración vertical y horizontal que analizamos previamente, así como también imponer la estrategia financiera basada en el autofinanciamiento como demostraremos en el siguiente apartado.

\section{LA ESTRATEGIA ECONÓMICA Y FINANCIERA DE FABRIL FINANCIERA}

\section{El capital y la inversión}

La constitución de Fabril Financiera tuvo lugar en el contexto del estallido de la gran depresión. Como se sabe, los primeros síntomas de la crisis en la economía argentina se anticiparon al crack de la Bolsa de Wall Street, producido en octubre de 1929. En efecto, a partir de mediados de 1928, Argentina sufrió una doble presión recesiva debido a la caída de los pre-

${ }^{12}$ Víctor Valdani, a poco de reincorporarse a la actividad empresarial, ocupaba sólo dos cargos directivos en el grupo Fabril. Por otro lado, Valdani era presidente del directorio de la Compañía General de Fósforos Sudamericana, una empresa que no estaba vinculada al grupo desde 1935. Hasta 1947, año de su fallecimiento, Juan Balbi había ocupado las presidencias de Fabril Financiera, Celulosa Argentina y Compañía Inmobiliaria Victoria, S. A. Carpeta Juan Balbi, CGFF.

${ }^{13}$ En la asamblea de 1956 Mario Segre, accionista y director propietario de Camoatí. Revista de Economía y Estadística, propuso un incremento del dividendo en efectivo y en acciones liberadas y expresó que los balances no reflejaban la realidad de la empresa. Su moción sólo fue apoyada por otros ocho accionistas. Libro de Actas de Asamblea General de Accionistas. núm. 2, 67 Asamblea, 8 de agosto de 1956. fol. 178, CGFF. 


\section{CUADRO 1. CARGOS DE DIRECTORES DE FABRIL FINANCIERA EN SOCIEDADES DEL HOLDING, 1948}

\begin{tabular}{|c|c|c|}
\hline Directores & Cargos en la CGFF & En otras sociedades \\
\hline Vittorio Valdani & Presidente & $\begin{array}{l}\text { Presidente de La Papelera Argentina, } \\
\text { Compañía Inmobiliaria Victoria, S. A. }\end{array}$ \\
\hline Francisco Patri & $\begin{array}{l}\text { Vicepresidente } \\
\text { delegado }\end{array}$ & $\begin{array}{l}\text { Presidente de Celulosa Argentina, } \\
\text { Electroclor, Talleres Coghlan, } \\
\text { PHILA; director suplente de } \\
\text { Compañía Inmobiliaria Victoria, S. A. }\end{array}$ \\
\hline Arq. Emilio Lavigne & Secretario & $\begin{array}{l}\text { Director de Celulosa Argentina; } \\
\text { director de la Compañía } \\
\text { Inmobiliaria Victoria, S. A. }\end{array}$ \\
\hline Andrés C. Scotto & Tesorero & Director de La Papelera Argentina \\
\hline Francisco Giraldez & Vocal & $\begin{array}{l}\text { Vicepresidente de La Papelera } \\
\text { Argentina y La Papelera del Plata; } \\
\text { director de Compañía Inmobiliaria } \\
\text { Victoria, S. A. }\end{array}$ \\
\hline Alberto Dellachá & Vocal & $\begin{array}{l}\text { Director secretario de Celulosa } \\
\text { Argentina; director suplente de } \\
\text { Compañía Inmobiliaria Victoria, S. A. }\end{array}$ \\
\hline Ing. Silvio Gagliardi & Vocal & $\begin{array}{l}\text { Vicepresidente de Electroclor; } \\
\text { vicepresidente y gerente de Celulosa } \\
\text { Argentina; director suplente de } \\
\text { Compañía Inmobiliaria Victoria, S. A. }\end{array}$ \\
\hline Ing. Ricardo Radaelli & Vocal & $\begin{array}{l}\text { Director secretario de La Papelera } \\
\text { Argentina y La Papelera del Plata }\end{array}$ \\
\hline Ing. Oscar Sassoli & Director gerente & $\begin{array}{l}\text { Presidente de Inquimar; vicepresidente } \\
\text { de PHILA y Talleres Coghlan; } \\
\text { director de La Papelera Argentina. }\end{array}$ \\
\hline Hugo Bagnardi & Síndico suplente & $\begin{array}{l}\text { Síndico suplente de La Papelera } \\
\text { Argentina }\end{array}$ \\
\hline
\end{tabular}

Fuente: elaboración propia con base en Carpeta Aumento de Capital, CGFF. 
cios internacionales de los cereales y el retiro de capitales de la plaza local. Estos procesos se acentuaron y obligaron a las autoridades a clausurar la Caja de Conversión en 1929 y, tras la declaración de inconvertibilidad de la libra en 1931, a apartarse definitivamente del patrón oro.

Entre 1928 y 1932, los precios de exportación cayeron 60\%, deprimiendo el ingreso del sector agrario e impactando sobre el comercio y la construcción. Como el precio de los productos importados descendió en menor medida, se produjo una fuerte caída de la capacidad de importación de la economía. Las tendencias depresivas se sintieron también en el sector industrial, aunque el impacto fue menor. En efecto, si bien la caída del ingreso generado por las exportaciones redujo la demanda interna, la aplicación del control de cambios y la devaluación de la moneda impulsaron la ISI. De esta forma, mientras el PBI se contrajo 14\% entre 1929 y 1932, la caída del sector manufacturero fue sólo de 6 por ciento.

La crisis sorprendió a Fabril Financiera en plena organización, pero con una sólida situación financiera. En su primera memoria, la empresa expresó así las dificultades del momento: "nuestras industrias han tenido que luchar con grandes dificultades, que son bien conocidas porque abarcan todas las actividades del país, y sólo hemos podido aminorar sus efectos gracias a las continuas mejoras que introducimos en nuestras instalaciones y en nuestra organización". ${ }^{14}$

El año más crítico parece haber sido 1930, cuando la empresa enfrentó un grave conflicto gremial en sus talleres gráficos que se prolongó desde julio hasta comienzos de 1931. Al mismo tiempo, la producción de algodón e hilados se vio muy comprometida por la caída de los precios internacionales y "la competencia encarnizada de los industriales extranjeros, empeñados en mantener su producción a costa de cualquier sacrificio". ${ }^{15}$ Estas circunstancias condujeron al directorio a poner en marcha políticas comerciales muy activas para colocar su producción, especialmente en el caso de los hilados de algodón y del aceite. ${ }^{16}$

A las dificultades creadas por el descenso en la demanda se sumaron problemas coyunturales de falta de liquidez, ocasionados por adelantos concedidos a dos de sus empresas vinculadas (Compañía General de Fósforos Sudamericana y Compañía Ítalo Argentina de Materiales Textiles). En abril de 1930, Fabril Financiera se vio obligada a tomar un crédito de corto plazo por 200000 pesos a una tasa de interés de $6.5 \%$, que resultó

${ }^{14}$ Memoria del ejercicio 1929-1930, CGFF.

${ }^{15}$ Memoria del ejercicio 1930-1931, CGFF.

${ }^{16}$ Se incrementaron los anuncios en la prensa y se contrataron más corredores para captar la demanda de los pequeños talleres de tejeduría. Actas 14, 26 de febrero de 1930, y 15, 12 de marzo de 1930, en Libro de Actas de Directorio, núm. 5, fols. 271 y 372, respectivamente, CGFF. 
favorable en relación con el promedio de la época (7.2\%) (Della Paolera, 1994). ${ }^{17}$

Las dificultades continuaron hasta 1933. Durante estos años, las fábricas mantuvieron su producción en un "volumen satisfactorio" a costa de reducir el margen de beneficios. ${ }^{18}$ A partir de 1934, la situación mejoró notablemente y el directorio consideró que los resultados obtenidos eran "satisfactorios".

En la gráfica 1 se observa la evolución del capital y del patrimonio neto en pesos constantes. Ambas series muestran un comportamiento particular con un gran incremento en los años de la segunda posguerra y una caída a principios de la década de 1950. Estas fluctuaciones están vinculadas a dos razones principales: por un lado, la fuerte caída de los años cincuenta da cuenta del impacto de la inflación sobre la evolución de las empresas. Si bien Fabril Financiera incrementó notablemente su capital y patrimonio durante esa década, la evolución de esas cuentas muestra una caída notable, es decir, el incremento de capital no alcanzó el ritmo de la inflación. En segundo lugar, las fluctuaciones del capital y patrimonio neto desde sus primeros años de actividad son el resultado de la particular estrategia financiera de la firma. Desde su fundación, Fabril Financiera continuó con las prácticas de la Compañía General de Fósforos de realizar importantes amortizaciones anuales para constituir nuevos fondos de reservas. Las amortizaciones sobre el activo tuvieron como resultado la reducción de los beneficios y el castigo a los accionistas, pero al mismo tiempo brindaron mayor solidez patrimonial a la firma. Esta política "conservadora" impactaba sobre la evolución de la cuenta de activo fijo y, especialmente, sobre la de maquinarias y equipos. El activo fijo en propiedades y edificios era amortizado en razón de $2 \%$ anual, mientras a maquinarias y equipo se les aplicaba $8 \%$ por el mismo concepto, y a los bienes muebles un porcentaje entre $10 \%$ y $20 \%$. Las amortizaciones realizadas alejaron progresivamente las cuentas de la empresa de su verdadero valor y dejaron de reflejar la evolución de las inversiones.

Las dificultades creadas por la segunda guerra mundial reforzaron esta política de "cautela". El conflicto reservó el mercado interno para la industria local, pero al mismo tiempo colocó a todos los sectores de la economía argentina frente a diferentes tensiones. Para la industria, los años de la guerra estuvieron marcados por un consumo intenso del stock de capital instalado, que no pudo renovarse por la ausencia de oferta de la industria local de fabricación de equipos y la reducción de las importaciones. A ello se sumó el incremento de los precios y la escasez de insumos bási-

${ }^{17}$ Acta 19, 20 de abril de 1930. Libro de Actas de Directorio, núm. 5, fol. 378, CGFF.

${ }^{18}$ Memoria del ejercicio 1931-1932, CGFF. 


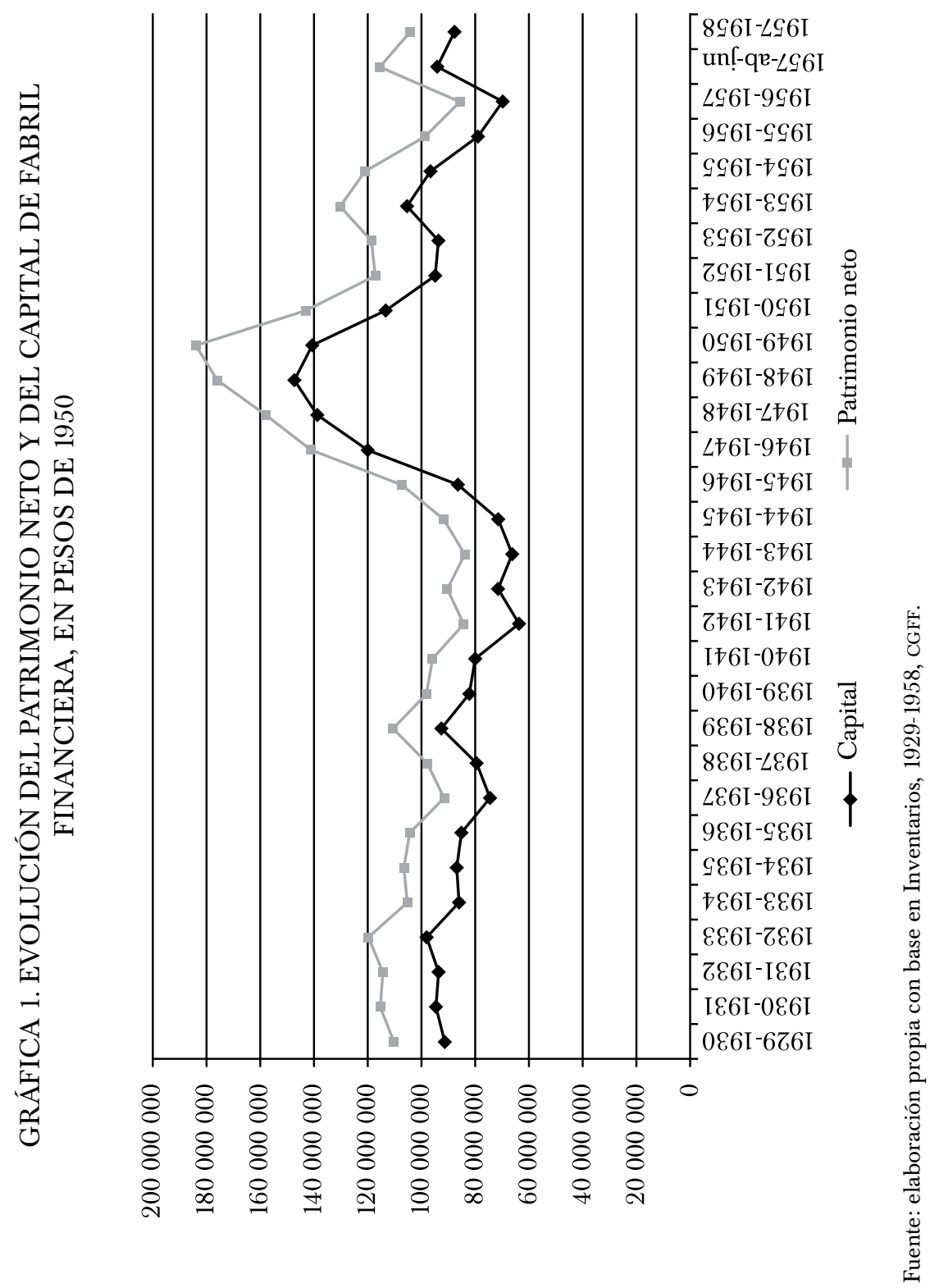


cos (combustibles, materias primas y accesorios industriales). Todo ello no impidió el crecimiento industrial, que durante la década de 1940 alcanzó una tasa anual de 5\%, pero sí lo condicionó, al limitar la sustitución de importaciones.

Para la empresa la situación no fue menos compleja. Si bien la guerra limitó la posibilidad de realizar ampliaciones y renovación de los equipos industriales, también es cierto que se siguieron aplicando porcentajes similares de amortización. Pero además, el consejo de administración logró que la asamblea de accionistas aprobara la realización de amortizaciones extraordinarias. En 1940, por ejemplo, se destinaron 628000 pesos $-22 \%$ de las ganancias líquidas- con ese fin. Dos años más tarde se autorizó a los directores a separar 795468 pesos para amortizaciones extraordinarias "con el fin de poner nuestras industrias, especialmente las de hilados de algodón, en mejores condiciones para resistir a la inevitable competencia futura". ${ }^{19}$ Entre 1937 y 1942, mientras el activo fijo ascendió de 12700000 de pesos a 21400 000, el porcentaje de amortizaciones se elevó de 7 a 21\% del total del activo fijo. En el rubro maquinarias el proceso fue muy notable. Si bien se había duplicado en valor entre 1937 y 1942, el porcentaje de amortizaciones ascendió de 11 a 63\% del total (Camoatí, julio, 1942, núm. 26, p. 16).

Al comenzar la posguerra, en 1947, las amortizaciones alcanzaban $60 \%$ del activo fijo y $72 \%$ de la cuenta maquinarias. Tres años más tarde, en 1950, los niveles eran similares: 50 y 71\% respectivamente. Sólo el fuerte impulso a las inversiones en ampliación durante la década de 1950 provocó un descenso importante del nivel de amortizaciones, alcanzando a 32 y $42 \%$ del activo fijo y el equipo productivo respectivamente (Camoatí, septiembre, 1955, núm. 184, p. 240).

A partir de los años cincuenta el proceso inflacionario afectó esta estrategia. Con orígenes diversos, entre los que se destacaron las políticas monetarias y crediticias expansivas y los desequilibrios de la estructura productiva, la inflación local se distanció de la internacional alcanzando tasas anuales del orden de 25 a 30\%. Por supuesto, este fenómeno ponía en serio riesgo las finanzas de la empresa ya que desvalorizaba el monto de las amortizaciones calculadas sobre el valor de libros de los bienes. Se trató de un fenómeno general que amenazó con provocar una fuerte descapitalización de las empresas. En 1948, ante la aceleración inflacionaria y el programa de ampliaciones de la empresa, el directorio aconsejó a los accionistas efectuar amortizaciones más amplias que las de práctica, sobre

${ }^{19}$ Libro de Actas de Asamblea General de Accionistas, núm. 2, 53a. Asamblea, 17 de junio de 1942, f. 89, CGFF. 
todo en maquinaria y bienes muebles, "para no correr el riesgo de presentar balances que no corresponden a la verdadera realidad del momento". ${ }^{20}$

La estrategia previsora de la empresa se expresó también en la creación de nuevos fondos que tenían semejantes resultados sobre la situación patrimonial y la distribución de ganancias. En el primer ejercicio, Fabril poseía además de la reserva legal, cuatro fondos adicionales (previsión, seguros, pensiones, accionistas). En total el monto de las reservas representaba 33\% del capital suscrito y realizado. En los años treinta se crearon otros dos fondos denominados "diferencia de cambios" (1933) y "leyes sociales" (1938), en tanto que el monto de las reservas alcanzó a representar $37 \%$ para 1938. Con el estallido de la segunda guerra mundial, el directorio reforzó esta política y, entre 1942 y 1943, ordenó constituir otros tres fondos de reservas: "primas sobre emisión de acciones", "fluctuación de valores" y "reserva servicios sociales". Según el consejo de administración, estos fondos servirían para cubrir futuras contingencias por la emisión de acciones, las fluctuaciones de los precios durante la posguerra y la atención a los servicios sociales de los asalariados. ${ }^{21} \mathrm{El}$ monto de las nuevas reservas elevó las mismas a $66 \%$ del capital. A principios de la siguiente década esta política se acentuó con la creación de dos fondos: "especial" (1951) y "ley 11.682/52 de Amortizaciones" (1952). Esto revelaba el cuidadoso seguimiento que el directorio realizaba de los programas de inversión de la empresa en un contexto inflacionario. Como resultado de esta política previsora, entre 1950 y 1955 las reservas se mantuvieron entre 44 y $56 \%$ del capital suscrito y realizado.

La política de amortización y la formación de fondos fue la base de la expansión del capital de la empresa y, como había destacado Valdani en 1938, la misma continuaba la estrategia seguida por la Compañía General de Fósforos desde sus orígenes en 1889. Por cierto, sólo una vez en 50 años la empresa había recurrido a la integración de nuevos capitales. En las otras ocasiones el aumento del capital había provenido de la capitalización de reservas o de la revaluación de los activos ya amortizados. ${ }^{22}$

En 1938 se decidió incrementar el capital autorizado hasta los 50000000 de pesos, monto que se alcanzó en 1946 por sucesivas emisiones de acciones destinadas a integrarse en otras empresas o bien a adquirir propiedades. En los años de posguerra, el incremento del capital continuó ininterrumpidamente. En 1946 se capitalizó una parte del fondo "prima

${ }^{20}$ Libro de Actas de Asamblea General de Accionistas, núm. 2, 59a. Asamblea, 16 de junio de 1948, fol. 142, CGFF.

${ }^{21}$ Libro de Actas de Asamblea General de Accionistas, núm. 2, 54a. Asamblea, 14 de junio de 1943, fol. 98, CGFF.

${ }^{22}$ Libro de Actas de Asamblea General de Accionistas, núm. 2, 49a. Asamblea extraordinaria, 17 de marzo de 1938, fol. 54, CGFF. 
sobre acciones" y de los beneficios obtenidos, mediante la emisión de acciones. Este último mecanismo se hizo usual como forma de aumentar el capital realizado que ascendió año tras año, con excepción del ejercicio 1954-1955. Ello obligó a la empresa a incrementar nuevamente el capital autorizado hasta los 150000000 en 1948; 300000000 al ejercicio siguiente y 1200 millones en 1957. Como dijimos, estos montos de capital fueron integrados por la capitalización de parte de los beneficios y la emisión de acciones para la compra de nuevas empresas y propiedades. ${ }^{23}$

La política de castigar a los accionistas a través de la formación de fondos, amortizaciones extraordinarias y la entrega de acciones en concepto de dividendo generó tensiones, particularmente en los años cincuenta. En 1949, el directorio propuso que de un monto total de 33000000 se abonase a los accionistas 14600000 pesos en efectivo y 18300000 en acciones liberadas. Un accionista se opuso argumentando:

Así como la sociedad en los últimos tiempos debió aumentar y pagar a sus obreros y empleados, el máximo de los recursos que le son indispensables para su bienestar, como lo establece la Constitución argentina en sus nuevos preceptos de bienestar e igualdad social, los accionistas reclamaban se les pague el máximo de los beneficios que produzcan sus economías del trabajo convertidas hoy en capital de la Sociedad, porque esos recursos les eran indispensables también para la subsistencia de sus hogares. ${ }^{24}$

La mayoría de los accionistas rechazó la propuesta precedente, pero la misma era una manifestación de las tensiones que originaba estas estrategias en el marco de una economía inflacionaria.

\section{La rentabilidad}

$\mathrm{El}$ análisis de la rentabilidad patrimonial revela el impacto del entorno macroeconómico en el que se desenvolvió Fabril y de las estrategias "cautelosas" impuestas por el consejo de administración. Durante la década de 1930, la rentabilidad patrimonial que había alcanzado 9.7\% en el primer ejercicio se mantuvo por debajo de ese porcentaje hasta la segunda guerra mundial. El punto más bajo se tocó en el ejercicio 1933-1934, con 5\%, en el momento en que se iniciaba la fase de ascenso del ciclo económico. La crisis externa de 1938 afectó particularmente a la industria textil, redu-

\footnotetext{
${ }^{23}$ Carpeta Aumento de Capital. CGFF.

${ }^{24}$ Libro de Actas de Asamblea General de Accionistas, núm. 2, 60a. Asamblea, 15 de junio de 1949, fol. 151, CGFF.
} 
ciendo sensiblemente la rentabilidad de Fabril. Sin embargo, este déficit fue compensado por primera vez por los beneficios obtenidos en la industria papelera. ${ }^{25}$ Esta situación se prolongó hasta comienzos de la segunda guerra mundial, de manera que en 1940 el directorio no dudó en afirmar que "Las industrias del papel y de la celulosa en las cuales la compañía ha aumentado sus intereses han producido, como en años anteriores, beneficios satisfactorios; otras industrias, en cambio, han debido también en este ejercicio sufrir la competencia motivada por la superproducción"26 (véanse gráficas 2 y 3 ).

A pesar de este comienzo difícil, los años de la guerra estuvieron marcados por un incremento importante de la rentabilidad que ascendió de 10 a $18 \%$ entre 1940 y 1944 . Todo ello es consistente con el aumento de la actividad industrial y la diversificación de la producción a través de nuevas empresas controladas por Fabril. La rentabilidad patrimonial ascendió vertiginosamente entre 1946 y 1949, alcanzando niveles extraordinarios debido a la realización de importantes ventas de acciones, el aumento de los beneficios industriales y dividendos percibidos en acciones liberadas de las empresas controladas. La empresa madre justificaba la venta de acciones de su cartera (fundamentalmente de Celulosa Argentina), en un momento de auge de la bolsa de valores porteña, con el propósito de mejorar la liquidez para financiar el plan de expansión de posguerra. Como veremos, esta práctica estaba relacionada con su política de no recurrir al crédito bancario.

En la década de 1950, incluso durante la crisis industrial de 1952-1953, la rentabilidad mostró un nivel positivo en porcentajes similares a los alcanzados en los inicios de la guerra. Durante los años cincuenta la venta de acciones ocupó un lugar marginal en las ganancias de la empresa. De todas maneras, la evolución de la rentabilidad se vio afectada por diversos factores, entre los que se destacaron el incremento del patrimonio neto, el aumento de las inversiones realizadas por la empresa y la reducción de las ganancias, que se vieron muy afectadas por las políticas de controles de precios aplicadas sobre la industria textil. Estas políticas, que surgieron durante la guerra, tuvieron un efecto negativo sobre la industria a partir de 1950, cuando la inflación erosionó el poder de compra de los salarios. Este proceso afectó a empresas que, como Fabril Financiera, elaboraban artículos de consumo masivo. ${ }^{27}$

${ }^{25}$ Libro de Actas de Asamblea General de Accionistas, núm. 2, 50a. Asamblea, 14 de junio de 1939, fol. 72, CGFF.

${ }^{26}$ Libro de Actas de Asamblea General de Accionistas, núm. 2, 51a. Asamblea, 12 de junio de 1940 , fol. 78, CGFF.

${ }^{27}$ El proceso continuó incluso luego del derrocamiento de Perón, en 1955. Así, por ejemplo, en abril de 1956, el directorio sostuvo que a pesar de que las fábricas se mantenían en plena 


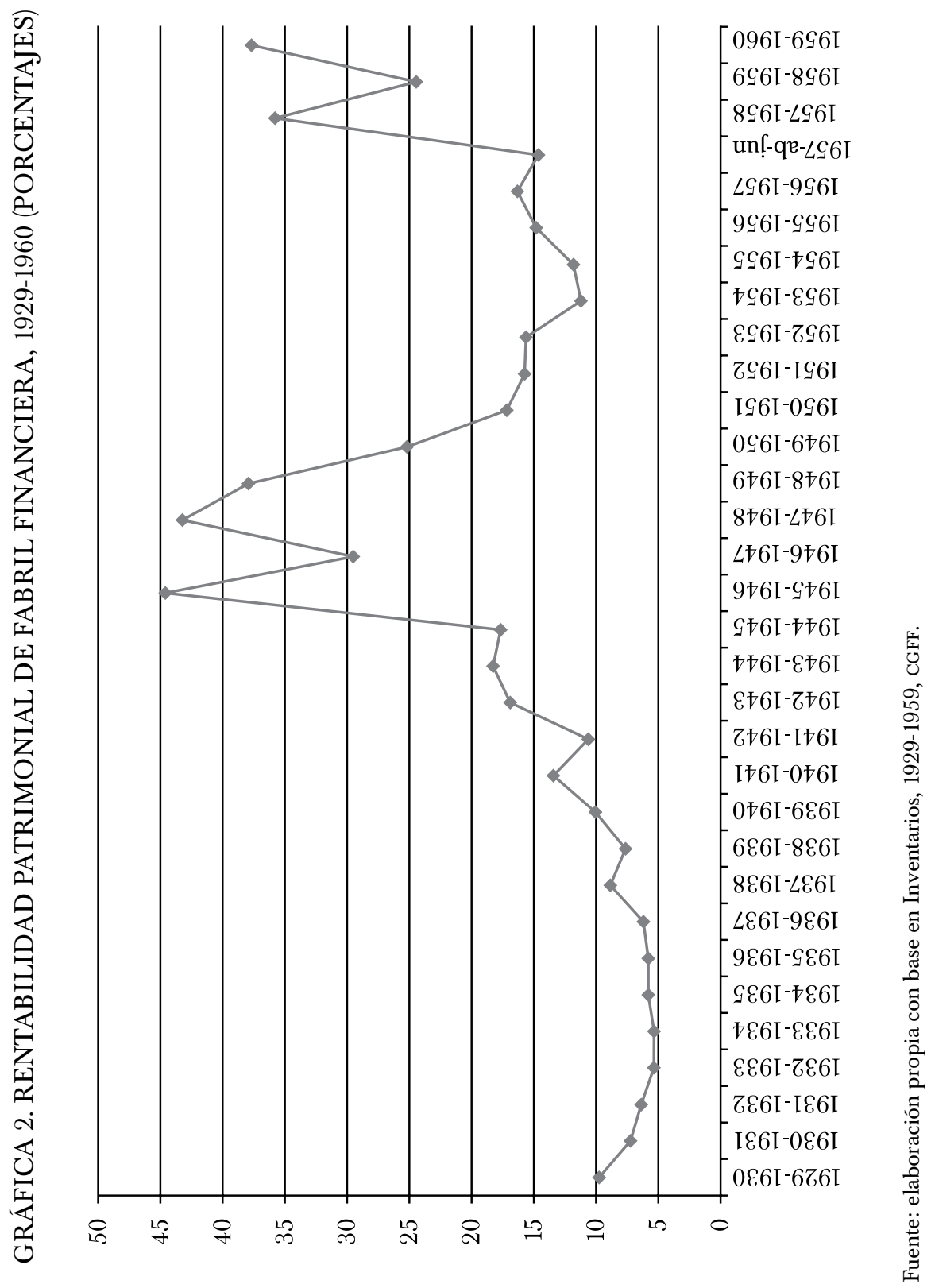




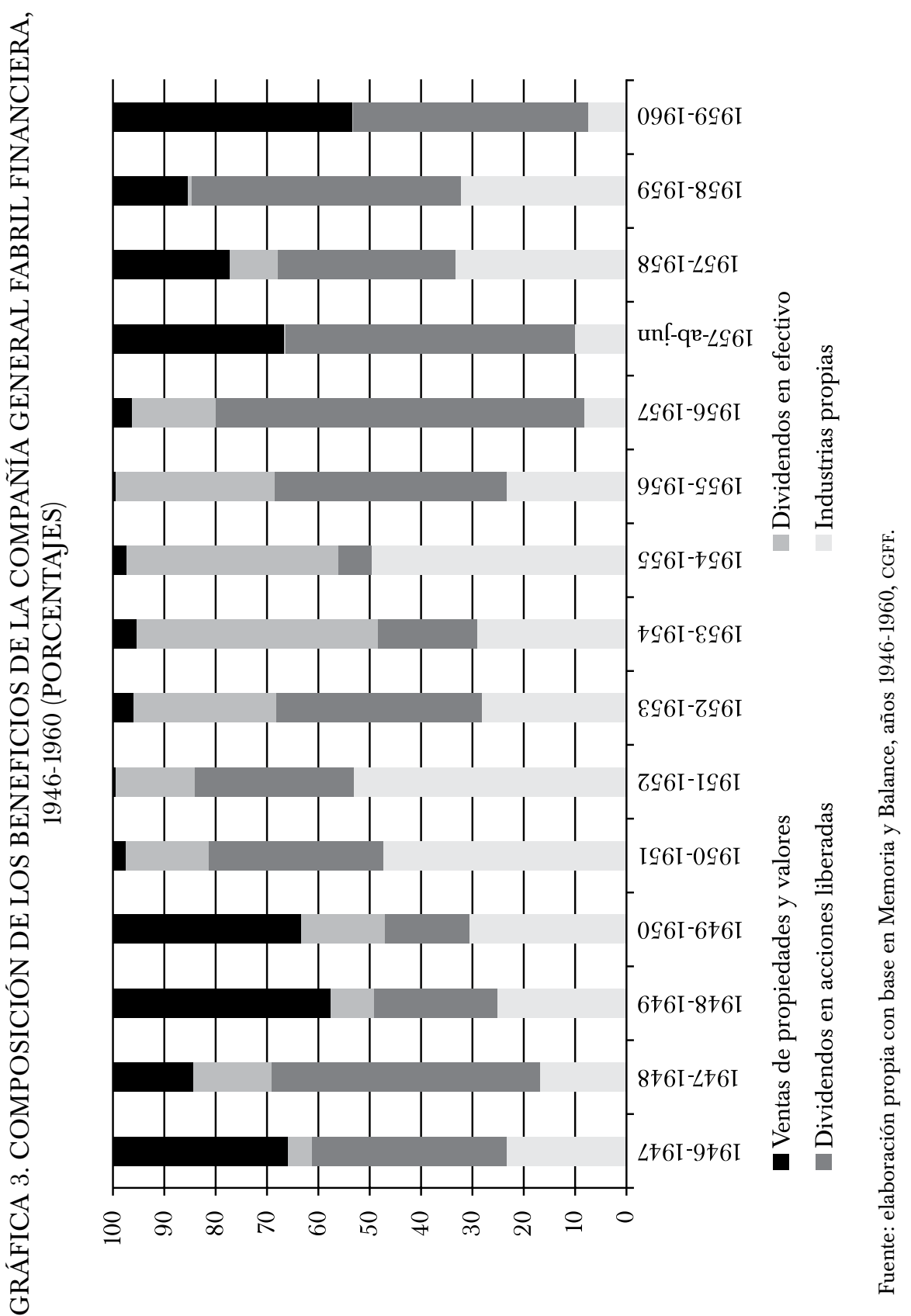


En los últimos tres ejercicios, al igual que en la posguerra, la rentabilidad ascendió nuevamente por la realización de ventas de acciones, el aumento de dividendos percibidos en acciones liberadas de las empresas controladas y de los beneficios industriales, a excepción del ejercicio 19591960 , en que estos se vieron disminuidos notoriamente en el marco del plan de estabilización monetaria aplicado por el gobierno de Frondizi.

El análisis de la composición de los beneficios muestra la conversión de la empresa en un holding industrial y la importancia de los ingresos provenientes de las sociedades anónimas controladas por Fabril. Entre 1946 y 1960, los ingresos por industrias propias (aceite de algodón, textil y gráfica) no superaron $52 \%$ del total, y en ocasiones representaron un porcentaje muy menor como en 1956, 1957 y 1959, cuando fueron solamente 8, 10 y 7\% del total, respectivamente. En cambio, Celulosa Argentina, la mayor empresa del holding controlada por Fabril, obtenía para 1951 la casi totalidad de sus beneficios de la actividad industrial (Camoatí, abril, 1951, núm. 131, p. 122).

En 1957, el directorio de Fabril Financiera destacó la escasa importancia de los beneficios de la producción propia, haciendo notar que hubiesen sido menores si las amortizaciones permitidas se ajustaran al contexto de alta inflación. ${ }^{28}$ Algunos años fueron muy excepcionales debido a que se obtuvieron beneficios extraordinarios de la venta de acciones de cartera, lo que disminuía la participación de los beneficios obtenidos por sus fábricas e incluso por los dividendos de las empresas controladas por Fabril. Esto sucedió en 1946, 1948, 1949 y 1957. En cambio, durante la década peronista se acentuó y mucho la importancia de los ingresos provenientes de las firmas controladas por Fabril, especialmente las papeleras. Estos dividendos eran abonados tanto en efectivo como en acciones. En cualquier caso, esta evolución en la composición de los beneficios muestra que Fabril Financiera se nutría más de sus inversiones en otras sociedades, principalmente las empresas papeleras, antes que en su producción de aceite, textil y gráfica. Por este motivo, dado el origen de sus beneficios, era más financiera que fabril.

actividad, "los beneficios de las industrias propias resultan notablemente inferiores a los del año anterior. Ello es debido a la congelación de precios de nuestros productos (especialmente los de nuestra fábrica de hilados) y al aumento de sueldos y salarios que, como es notorio, deben ser absorbidos por las ganancias". Memoria del ejercicio 1955-1956, CGFF.

${ }^{28}$ Libro de Actas de Asamblea General de Accionistas, núm. 2, 69a. Asamblea, 16 de octubre de 1957, fol. 190, CGFF. 


\section{Expansión basada en el autofinanciamiento}

Fabril Financiera continuó y profundizó la estrategia financiera de la Compañía General de Fósforos consistente en basar el crecimiento de la firma a partir de los recursos propios (Badoza y Belini, 2009). En la gráfica 4 puede observarse la evolución del coeficiente de endeudamiento de Fabril Financiera entre 1930 y 1960, entendido como la razón de los recursos ajenos sobre los recursos propios. Como se desprende de su evolución, entre 1929 y 1960, Fabril Financiera se expandió predominantemente sobre los recursos internos. Los recursos ajenos empleados sólo excepcionalmente superaron $20 \%$ del total y ello fue por un periodo muy breve en la coyuntura de la crisis industrial de 1952-1953, cuando alcanzaron 33\% del total de los recursos empleados. Asimismo, se observan fluctuaciones importantes durante las décadas de 1930 y 1950. Sin embargo, resalta que en la década de 1940 el coeficiente de financiamiento muestra un nivel bajo, entre 7 y $9 \%$. Por un lado, luego de finalizada la guerra, se inicia un periodo de planes e inversiones para la modernización y ampliación de las fábricas, programa que adquirió mayor ritmo a partir de los años cincuenta. Como sabemos, la empresa amplió su patrimonio mediante la capitalización de las reservas en esos años para hacer frente a las nuevas inversiones.

Por otra parte, el reforzamiento de esta estrategia de autofinanciamiento es llamativo si consideramos que a partir de 1944 el Banco de Crédito Industrial se convirtió en una importante fuente de capitales para las grandes y pequeñas empresas, las cuales se beneficiaron del otorgamiento de créditos a tasas de interés reales negativas. Fabril Financiera no recurrió a esa fuente de capitales y continuó con su política destinada a reforzar la autonomía financiera de la empresa. Ello requiere de una explicación más amplia ya que la oferta de crédito barato hubiera permitido a la empresa contar con un subsidio encubierto, y porque además, como han demostrado diversos estudios (Girbal-Blacha, 2003; Rougier, 2001), grandes empresas argentinas emplearon ampliamente este recurso. En cualquier caso, es claro que las deudas tuvieron más bien un papel muy modesto. Aunque otras empresas del grupo, entre ellas Celulosa Argentina, Talleres Coghlan y PHILA se beneficiaron de ese apoyo crediticio de corto plazo para adquirir materias primas y pago de salarios.

¿Cuál era la composición de los recursos externos empleados? Entre 1929 y 1934, las deudas con interés y las deudas en cuenta corriente contribuyeron en partes iguales al total de los recursos ajenos empleados. Entre las primeras, predominaron las deudas hipotecarias heredadas de la Compañía General de Fósforos: la hipoteca que pesaba sobre el Taller Gráfico Radaelli. Las deudas bancarias con interés eran muy menores y se limitaban al crédito solicitado al Banco de Italia y Río de la Plata, ins- 


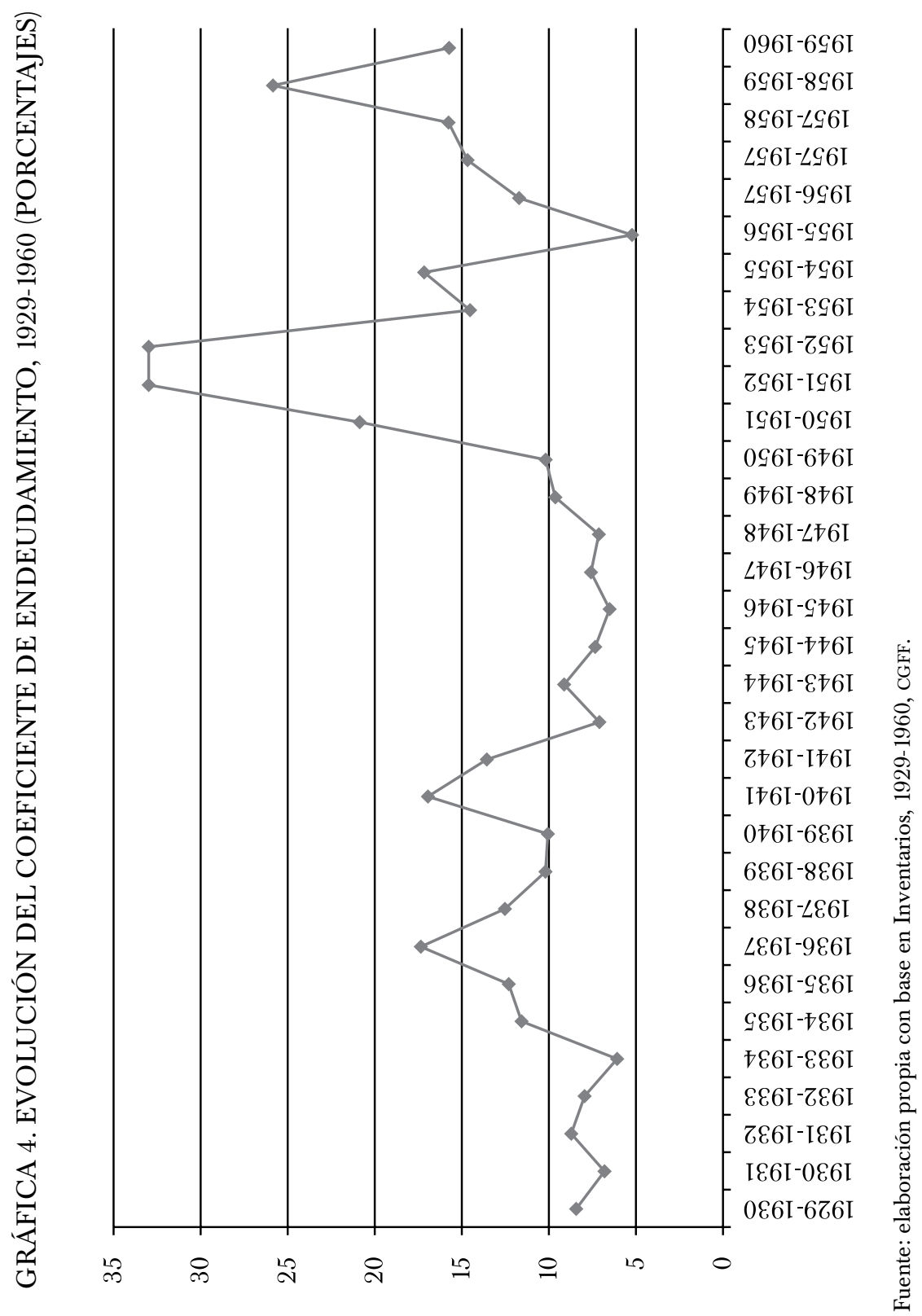


titución que ha sido vista por diversos autores como la cabeza del Grupo Italiano o incluso como la sociedad financiera del Grupo Fabril (Barbero, 2000; Schvarzer, 1996).

A partir del ejercicio 1934-1935, el pasivo exigible de la empresa se componía casi exclusivamente de deudas a corto plazo, deudas comerciales, cuentas corrientes, trabajos facturados y otras cuentas. Recién a comienzos de la década de 1950, la empresa volvió a contraer deudas con interés representando entre 25 y 35\% de los recursos externos. En este caso, no se trató de hipotecas sino de obligaciones. Para el ejercicio 1956-1957, Fabril tenía colocadas obligaciones en diversas instituciones bancarias que en orden de importancia eran las siguientes: Banco Provincia de la Buenos Aires, Banco de Italia y Río de la Plata, Banco Galicia, Banco Ítalo Belga, Nuevo Banco Italiano y Royal Bank of Canada. ${ }^{29}$

$\mathrm{El}$ análisis de las fuentes de recursos empleados y el papel de los recursos internos y externos en la estrategia financiera de la empresa madre permite interrogarnos en qué medida Fabril Financiera se distanciaba de otras grandes empresas argentinas de la época. No contamos con estudios amplios sobre estas cuestiones y desde la perspectiva de la historia de empresas los trabajos publicados no han explorado esta dimensión, en parte debido a la falta de archivos contables. Un estudio realizado por el Banco Central sobre 285 sociedades anónimas industriales muestra que entre 1955 y 1959, 66\% de los recursos empleados fueron externos, en tanto que sólo 34\% provino de fuentes internas. La estadística muestra también que entre los recursos externos la fuente principal provino de los préstamos (35\%), fundamentalmente de orden comercial. En cambio, los créditos bancarios sólo habrían constituido $12.6 \%$ de los recursos empleados (Banco Central de la República Argentina, 1961, p. 5). Un análisis sobre las finanzas de la empresa muestra que Fabril Financiera se alejaba considerablemente de ese patrón. La empresa se destacaba por su estrategia de autofinanciación y su bajo coeficiente de endeudamiento. Entre 1955 y 1959, el origen de los recursos empleados fue sustancialmente diferente ya que los recursos internos representaron $85 \%$ del total y los externos sólo el 15\% restante. Asimismo, entre las fuentes externas de capital, las deudas comerciales y otras a corto y mediano plazos constituían $46 \%$, las deudas bancarias representaban $40 \%$ (principalmente compuestas por obligaciones) y el resto estaba integrado por deudas financieras.

En resumen, en el periodo bajo estudio, Fabril Financiera continuó y profundizó la estrategia basada en el autofinanciamiento y el fortalecimiento de la autonomía económica de la empresa. La realización de grandes amortizaciones y la formación de nuevas reservas permitieron a

${ }^{29}$ Libro de inventario, núm. 4, fols. 399-400, CGFF. 
la firma sucesivas ampliaciones del capital y el financiamiento de la expansión de las fábricas propias dedicadas a las artes gráficas y al complejo algodonero, y la adquisición y control de un destacado grupo de firmas industriales. Además, esta estrategia fue posible por la concentración de la propiedad de la empresa en un grupo de familias accionistas y su control sobre el gobierno corporativo, lo que permitió implementar una política que, al reducir los beneficios, perjudicaba los intereses de los accionistas minoritarios. El predominio del autofinanciamiento contrasta con el papel limitado que desempeñaron las fuentes externas de capital. El lugar marginal de estos recursos se vio acentuado por el tipo de deudas contraídas que fueron fundamentalmente comerciales y de corto plazo, y sólo excepcionalmente deudas de mediano y largo plazos (hipotecas, obligaciones y créditos). Esta estrategia de reforzamiento de la autonomía financiera de la firma es congruente con el fortalecimiento de Fabril Financiera y su constitución como empresa madre de un Grupo Industrial. A pesar de las transformaciones que se produjeron en el sistema financiero argentino, $\mathrm{y}$ el importante papel cumplido por los bancos estatales en el financiamiento a la industria a partir de 1944, Fabril Financiera fue renuente a tomar créditos de esa procedencia. Esta estrategia se puede entender como una política deliberada para mantener la autonomía del Grupo Fabril frente al Estado en un momento en que se produjeron conflictos con el gobierno peronista por la adquisición de Manufacturera Algodonera Argentina.

\section{CONSIDERACIONES FINALES}

En este estudio de caso sostenemos que, a diferencia de los grupos económicos diversificados en las finanzas, el agro, la industria y los servicios durante el periodo de la ISI en Argentina, Fabril Financiera constituyó uno de los pocos ejemplos de grupo industrial de diversificación relacionada en sus principales actividades productivas: textil, papel y artes gráficas. A partir del análisis de la documentación proveniente del archivo de la empresa, afirmamos que Fabril Financiera se convirtió en la cabeza del grupo, apartándonos de los estudios "genéricos" que privilegiaban el vínculo con el sector financiero, en este caso con el Banco de Italia, o bien adjudicaban el liderazgo del grupo a Celulosa Argentina.

A semejanza de lo sostenido por la literatura sobre grupos para los países de América Latina y Asia, Fabril Financiera constituyó una forma específica de organización empresarial que se prolongó más allá del periodo bajo estudio. Nuestro análisis sobre el gobierno corporativo demuestra que no hubo en Fabril separación entre propiedad y gestión, como en la empresa moderna estadunidense analizada por Chandler. Como vimos 
a lo largo del trabajo, el conflicto no se presentó entre propiedad y gestión de la firma, sino entre los intereses de los accionistas mayoritarios y minoritarios.

Los principales accionistas y la dirección sostuvieron una particular estrategia de desarrollo de sus propios establecimientos y del holding en diversos y cambiantes procesos económicos e institucionales.

$\mathrm{El}$ análisis de la composición del directorio permite concluir que durante el periodo bajo estudio, sus principales miembros, que habían iniciado su carrera en la Compañía General de Fósforos, permanecieron y se afirmaron como centro de decisión de la empresa madre (cabeza del holding), y a través de la tenencia mayoritaria de las acciones de las otras sociedades condujeron el grupo entero. Con este fin, en las décadas sucesivas, el consejo de administración desarrolló una política "endogámica" a la hora de incorporar nuevos miembros, los que fueron seleccionados dentro del círculo de las familias fundadoras, los managers que habían hecho carrera en la propia empresa y, en menor medida, representantes de otras sociedades anónimas del grupo. A lo largo del periodo hubo más continuidades que cambios en el directorio dado que recién, a comienzos de la década de 1960, devino una renovación y un recambio generacional de los principales cuadros directivos.

El control de la empresa madre por un reducido grupo de accionistas que formaban parte del gobierno, junto a los managers, explicarían la continuidad de las estrategias financieras y económicas similares a las implementadas por su antecesora: la ampliación de capital y crecimiento del holding basada en el reparto de dividendos y la capitalización de reservas a través de acciones liberadas. El sostenimiento de esta política no implicó una estrategia conservadora del grupo. Por el contrario, la actuación de Fabril en distintas actividades productivas a través de la formación de sociedades, jurídicamente independientes, indujo a un proceso virtuoso de eslabonamientos hacia atrás y adelante en las ramas papelera, gráfica y textil.

En relación con las estrategias económicas y financieras, también observamos mayor continuidad y menores rupturas. Fabril Financiera profundizó la política basada en el autofinanciamiento y el fortalecimiento de la autonomía económica. La estrategia de autofinanciamiento consistió en la realización de importantes amortizaciones anuales para constituir nuevos fondos de reservas. Las amortizaciones sobre el activo tuvieron como resultado la reducción de los beneficios y el castigo a los accionistas y, al mismo tiempo, permitieron a la empresa alcanzar mayor solidez patrimonial.

Tanto la expansión de los establecimientos fabriles propios en las ramas de artes gráficas, algodón y textil como la participación y control de 
un grupo de firmas industriales, se realizaron a partir del autofinanciamiento, recurriendo excepcionalmente al mercado de valores y el crédito bancario. Por cierto, resulta significativo que durante el periodo posterior a 1944, cuando hubo mayor disponibilidad de crédito público para el financiamiento industrial en condiciones ventajosas, la empresa madre no recurrió a este tipo de endeudamiento tan frecuente en la época. Como afirma la literatura, los grupos en América Latina tendieron al autofinanciamiento. Desde la perspectiva de los accionistas mayoritarios y el directorio, la toma de préstamos significaba arriesgar el control y la autonomía de la firma, especialmente durante el gobierno peronista.

La estrategia de autofinanciamiento y la rentabilidad positiva, aun con las distorsiones que hemos señalado en el trabajo, explican la capacidad económica de Fabril Financiera para conformar un grupo industrial a partir de los recursos propios. Nuestro estudio de caso contradice dos de los supuestos más difundidos por la historiografía sobre los grupos económicos: la expansión de los mismos requería necesariamente la vinculación financiera y el favor gubernamental.

\section{LISTA DE REFERENCIAS}

Aldrighi, D. y Postali, F. (2010). Business Groups in Brazil. En A. Colpan, T. HikINO y J. Lincoln, The Oxford Handbook of Business Groups (pp. 353-386). Oxford: Oxford University Press.

Aspiazu, D., Basualdo E. y Khavisse, M. (1986). El nuevo poder económico en la Argentina de los años 80 . Buenos Aires: Hyspamérica.

BADOZA, S. (1997). Un lugar en el futuro a nuestro pasado. ¿El patrimonio industrial es patrimonio histórico? Trabajo inédito. Universidad Nacional de La Plata, Argentina.

BADOZA, S. (2008). De la integración vertical al mercado: el taller de artes gráficas de la Compañía General de Fósforos en las primeras décadas del siglo Xx. Estudios IberoAmericanos, 34(2), 13-30.

BAdoza, S. y Belini, C. (abril-junio, 2009). La Compañía General de Fósforos, 18891929: Expansión y límites de una gran empresa en una economía agroexportadora. Desarrollo Económico, 49(193), 91-121.

BADOZA, S. y Belini, C. (2013). Origen, desarrollo y límites estructurales de la industria del papel en la Argentina, 1880-1940. Revista de Historia Industrial. Economía y Empresa, 53(3), 109-141.

Banco Central de la República Argentina (1961). Inversiones y fuentes de recursos, balances agregados y resultados de un conjunto de sociedades anónimas nacionales. Años 1955-1959 (p. 5). Buenos Aires. 
Barbero, M. I. (2000). Mercados, redes sociales y estrategias empresariales en los orígenes de los grupos económicos. De la Compañía General de Fósforos al Grupo Fabril, 1889-1929. Estudios Migratorios Latinoamericanos, 44, 119-145.

Barbero, M. I. y Jacob, R. (comps.) (2008). La nueva historia de empresas en América Latina y España. Buenos Aires: Temas Editorial.

Belini, C. (julio-diciembre, 2010). La Compañía General de Fósforos y los orígenes de la industria hilandera de algodón en Argentina, 1920-1935. América Latina en la Historia Económica, 17(2), 93-126.

Bisang, R. (1996). Perfil tecno-productivo de los grupos económicos en la industria argentina. En J. KATZ (ed.), Estabilización macroeconómica, reforma estructural y comportamiento industrial. Buenos Aires: Comisión Económica para América Latina y el Caribe/International Development Research Centre/Alianza Editorial.

Camoatí. Revista de Economía y Estadística, años 1942, 1951, 1955, 1957.

Castro, C. (2008). Una multinacional dirigida desde Buenos Aires. La internacionalización temprana de Techint, 1946-1976. En G. Guajardo (coord.), Innovación y empresa. Estudios Históricos de México, España y América Latina. México: Universidad Nacional Autónoma de México.

Cerutti, M. (2011). Industria pesada y construcción de un grupo empresarial en el norte de México. Fundidora de Fierro y Acero de Monterrey (1900-1975). X Congreso Internacional de la Asociación Española de Historia Económica. Universidad Pablo de Olavide, Carmona, Sevilla.

Chandler, A. (1987). La mano visible. La revolución en la dirección de la empresa norteamericana. Madrid: Ministerio de Trabajo y Seguridad Social.

Chandler, A. (1996). Escala y diversificación: la dinámica del capitalismo industrial. Zaragoza: Prensas Universitarias, Zaragoza. Trad. esp. Jordi Beltran.

Colpan, A., Hikino, T. y Lincoln, J. (2010). Introduction. En A. Colpan, T. Hikino y J. LinCOLN, The Oxford handbook of business groups (pp. 1-9). Oxford: Oxford University Press.

Compañía General Fabril Financiera [CGFF] (1938). Estatutos vigentes. Buenos Aires: CGFF.

Compañía General Fabril Financiera [CGFF] (1949), Historia de un grupo de empresas industriales en la Argentina, 1888-1948. Buenos Aires: CGFF.

DÁvila, C. (comp.) (1996). Empresa e historia en América Latina. Un balance historiográfico. Bogotá: T. M. Editores/COLCIENCIAS.

Dávila, C., Vilora, J. y Elías-CARO, J. (comps.) (2013). Los estudios empresariales en Colombia a principios del siglo XXI (con una referencia a México). Santa Marta: Editorial de la Universidad de Magdalena.

Della Paolera, G. (1994). Experimentos monetarios y bancarios en Argentina: 18611930. Revista de Historia Económica, 12(3), 539-589.

Fracchia, E., MesQuita, L. y Quiroga, J. (2010). Business groups in Argentina. En A. ColPan, T. Hikino y J. LinCOLn, The Oxford handbook of business groups (pp. 325352). Oxford: Oxford University Press. 
Gaggero, A. (julio-septiembre, 2012). La retirada de los grupos económicos argentinos durante la crisis y salida del régimen de convertibilidad. Desarrollo Económico, 52(206), 229-254.

Gilbert, J. (2003). El grupo Tornquist entre la expansión y las crisis de la economía argentina en el siglo Xx. Ciclos, 25-26, 65-91.

Girbal-Blacha, N. (2003). Mitos, paradojas y realidades en la Argentina peronista, 19461955. Bernal: Universidad Nacional de Quilmes.

Hikino, T. y Amsden, A. (abril-junio, 1995). La industrialización tardía en perspectiva histórica. Desarrollo Económico, 35(137), 3-34.

HiLt, E. (2014). History of American corporate governance: Law, institutions, and politics. National Bureau of Economic Research Working Paper 20356. Recuperado de http://www.nber.org/papers/w20356

Hoshino, T. (2010). Business groups in Mexico. En A. Colpan, T. Hikino y J. LinCOLN, The Oxford handbook of business groups (pp. 424-455). Oxford: Oxford University Press.

Khanna, T. y YafeH, Y. (junio, 2007). Business groups in emerging markets: Paragons or parasites? Journal of Economic Literature, 55, 331-372.

La Porta, R., Lopez de Silanes, F. y Shleifer, A. (1999). Corporate ownership around the world. The Journal of Finance, 54(2), 471-517.

LEFF, N. (1978). Industrial organization and entrepreneurship in developing countries: The economics groups. Economic Development and Cultural Change, 26(4), 661-675.

Lefort, F. (2010). Business groups in Chile. En A. Colpan, T. Hikino y J. Lincoln, The Oxford handbook of business groups (pp. 387-423). Oxford: Oxford University Press.

LluCh, A. y SAlvaJ, E. (primer semestre, 2012). Fragmentación del empresariado en la época de la industrialización por sustitución de importaciones (ISI) en la Argentina: una aproximación desde el estudio de la red corporativa (1954-1970). Apuntes, 70, 135-166

Monsalve, M. (ed.) (2014), Grupos económicos y mediana empresa familiar en América Latina, Universidad del Pacífico, Lima.

Morck, R. K. (ed.). (2005). A history of corporate governance around the world: family business groups to professional managers. Chicago: University of Chicago Press.

Morck, R. K. y STEIER, L. (2005). The global history of corporate governance: An introduction. En R. K. MORCK (ed.), A history of corporate governance around the world: Family business groups to professional managers, Chicago, The University of Chicago Press.

Peres, W. (coord.) (1998). Grandes empresas y grupos industriales latinoamericanos. Expansión y desafíos en la era de la apertura y la globalización. México: Siglo XXI Editores.

Rougier, M. (2001). La política crediticia del Banco Industrial durante el primer peronismo, 1944-1955. Documento de Trabajo núm. 5. Universidad de Buenos Aires, Argentina. 
Rougier, M. (2011). Estado y empresarios en la industria del aluminio en Argentina. El caso ALUAR. Bernal: Universidad Nacional de Quilmes.

Schvarzer, J. (1989). Bunge y Born. Crecimiento y diversificación de un grupo económico. Buenos Aires: Centro de Investigaciones Sociales sobre el Estado y la Administración/Grupo Editor Latinoamericano.

SchVArZer, J. (1996). La industria que supimos conseguir. Buenos Aires: Planeta.

VALDAVISO, J. M. (2002). Grupos empresariales, marco institucional y desarrollo económico en España en el siglo xx: los negocios de la familia Aznar (c. 1937-c. 1983). Revista de Historia Económica, 20(3), 577-624.

\section{OTRAS FUENTES}

Archivos

CGFF Archivo Empresarial de la Compañía General de Fósforos y Compañía General Fabril Financiera, en Programa de Estudios de Historia Económica y Social Americana (PEHESA) del Instituto de Historia Argentina y Americana Dr. Emilio Ravignani, de la Facultad de Filosofía y Letras de la Universidad de Buenos Aires. 